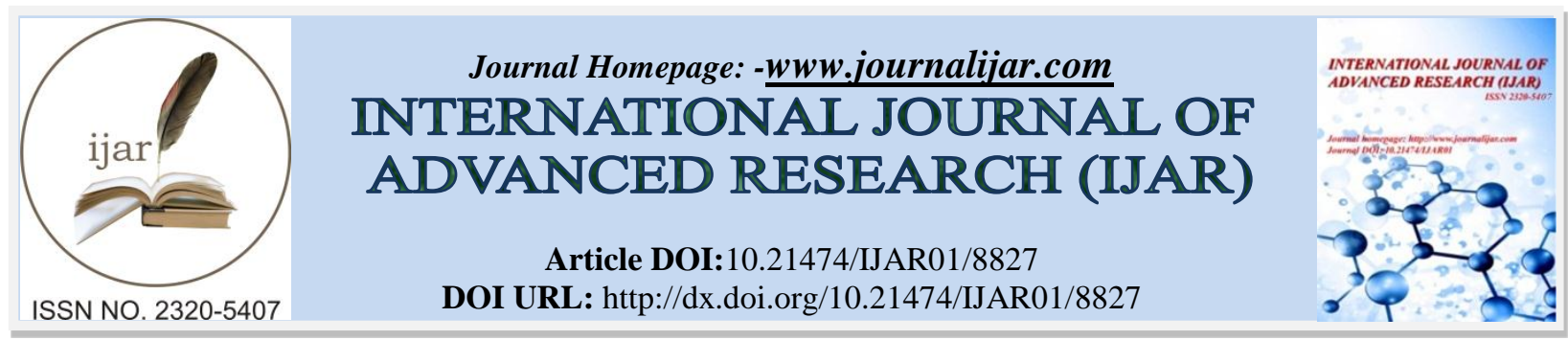

RESEARCH ARTICLE

\title{
FISH- MAPPING AND STANDARD GTG-BANDING KARYOTYPE OF THREE EGYPTIAN SHEEP BREEDS.
}

Mona E. Abd El-Gawad ${ }^{1}$, Hanaiya A. El-Itriby ${ }^{1}$, Hassan M. Sobhy ${ }^{2}$ and Ebtissam H. A. Hussein ${ }^{3}$.

1. National Gene Bank, Agriculture Research Center, Giza, Egypt.

2. Department of Natural Resources, Institute of African Research and Studies, Cairo University, Giza, Egypt.

3. Department of Genetics, Faculty of Agriculture, Cairo University, Giza, Egypt.

\section{Manuscript Info}

\section{Manuscript History}

Received: 06 February 2019

Final Accepted: 08 March 2019

Published: April 2019

Key words:-

Ovis aries, Sheep, Chromosomes,

Karyotype, GTG-banding, FISH.

\begin{abstract}
Standardized karyotyping by GTG- banding technique and physical chromosome mapping by Fluorescent in Situ Hybridization (FISH) were utilized to characterize the three Egyptian breeds of sheep (Barki, Rahmani and Ossimi). Blood samples were collected from 15 individuals from each breed of sheep. G-banded chromosomes revealed that the karyotype macrostructure was highly conserved and in considerable accordance to the standard karyotype of the Ovis aries. The chromosome diploid number was $54(2 n=54, X X / X Y)$. The karyotype formula was $2 \mathrm{n}, 54=\mathrm{L}_{6}^{\mathrm{m}}+\mathrm{M}^{\mathrm{a}}{ }_{22}+\mathrm{S}_{24}^{\mathrm{a}}+$ sex chromosomes. Physical chromosome mapping of the three breeds (Barki, Rahmani and Ossimi) was carried out by localization of two subtelomeric SSR and two (SPRN) related specific sequences. The two subtelomeric SSR sequences revealed six different loci in five chromosomes $(1 \mathrm{p} 37,1 \mathrm{p} 36$ and $17 \mathrm{q} 26$ with the EPCDV008 probe) and (2q45, 4q22 and $24 \mathrm{q} 24$ with the EPCDV016 probe), respectively. In addition the two (SPRN) related specific sequences were successful in differentiating among the three breeds. The probe OriaBAC273H7 hybridized to a similar locus (20q13) in breeds Rahmani and Ossimi, while, in Barki, it hybridized to a different locus (22q24). However, probe OriaBAC265G4 hybridized to three different loci (17q25, 22q24 and 20q13) in Barki, Rahmani and Ossimi, respectively.
\end{abstract}

Copy Right, IJAR, 2019,. All rights reserved.

\section{Introduction:-}

Conservation of animal genetic resources has become an urgent demand nowadays. This is due to the ever increase in human population, the global climate change and the risk of extinction of some valuable genetic resources. Therefore, conservation of genetic diversity is required to facilitate genetic improvement and selection, and to meet current production needs in various environmental conditions (Glowazki-Mullis et al., 2008 and Mekuriaw et al., 2016). Accurate characterization of livestock breeds is one of the main purposes of germplasm banks. Different methods are available to characterize livestock breeds at the cytogenetic level (Murphy et al., 2004). In addition, the molecular tools have increased the efficiency of germplasm characterization, thus assuring objective criteria for the conservation of genetic resources and establishment of genebanks (Liu et al., 2014). The study of chromosome structure and the precise identification of chromosomes using differential staining techniques such as G- banding 
and fluorescence in situ hybridization (FISH) markers constitute the first step in exploring chromosomal structure. In addition, establishing a standard chromosome nomenclature for each breed, as well as breed characterization at the molecular level, is important for the patent registration of national genetic resources. This information could be extremely useful in supporting breeding programs and would ultimately help to overcome the acute shortage in animal protein (Ali et al., 2011). The molecular techniques have so far been used in the molecular cytogenetic studies of bovid species including the river buffalo (Iannuzzi et al., 2001a and b), cattle (Fronicke and Wienberg, 2001 and Larkin et al., 2003), goat (Di Meo et al., 2003) and sheep (Iannuzzi et al., 2001b and Di Meo et al., 2003 and 2007).

During the last two decades, FISH technique has been widely used in domestic animals for different purposes. This has been applied to identify chromosomal rearrangements, gene mapping, comparative mapping and evolutionary chromosome studies (Farhadi et al., 2013).

In Egypt, sheep represent a valuable source of meat and milk production. There are several indigenous breeds (Othman et al., 2015). The three major Egyptian sheep breeds are Barki, Rahmani and Ossimi, representing 65\% of the total sheep population (EI Shennawy, 1995). These breeds are reared using minimal resources and are well adapted to local environmental conditions. Therefore, they could have acquired valuable alleles and allelic combinations that could be of importance in animal improvement and breeding programs. It is important to characterize a breed for its conservation (Mahmoudi et al., 2010). Yet, a few cytogenetic and molecular studies on sheep have been undertaken. Therefore, in the present investigation, GTG-banding and FISH markers were used in an attempt to provide fine standard karyotypic details and characterize the main Egyptian breeds of domestic sheep (Barki, Rahmani and Ossimi).

\section{Materials and Methods:- \\ Samples collection}

Forty five peripheral blood samples were collected from three domestic sheep breeds (Barki, Rahmani and Ossimi). Fifteen samples were taken from each breed. In addition. These materials were kindly provided by the Research and Experimental Station, Faculty of Agriculture, Cairo University. Whole blood samples of the three sheep breeds were collected through jugular venipuncture in heparinized and EDTA vacationers. The blood samples were kept at $4^{\circ} \mathrm{C}$ and transported to the Cytogenetics and Molecular Genetics Labs at the National Gene Bank, ARC, Egypt.

\section{-Karyotype Analysis \\ Cell culture}

The lymphocytes were cultured using the whole blood microculture technique described by Kenthao et al. (2012) with minor modifications. .

\section{-Unbanded karyotype}

Fifteen cells of well-spread mitotic metaphase plates were used for chromosome measurements. The length of short $\operatorname{arm}(\mathrm{p})$ and the long arm (q) of each chromosome were measured and the total length (TL) was calculated as (p + q). The relative length (RL \%) of each chromosome was estimated in percent of total length of complement according to the formula ((TL/sum TL) x100). While, the formula used for the centromeric index (CI \%) was ((p/TL) x100) according to Supanuam et al. (2009) and Ekambaram et al. (2011). CI \% was employed to determine the chromosomes type according to Chaiyasut (1989). The numbering and nomenclature of the chromosomes were given as reported by Ford et al. (1980) in the Proceedings of the First International Conference for the Standardisation of Banded Karyotype of Domestic Animals.

\section{-GTG-banding technique}

The GTG-banding technique was applied on the metaphase chromosomes of the sheep breeds under investigation. The GTG-banding technique was adopted from Kenthao et al. (2012). The slides were dried on air and then soaked in working trypsin (0.025\% trypsin EDTA) at $37^{\circ} \mathrm{C}$ until the termination of trypsin activity (5 to 10 seconds) by washing the slide with phosphate buffer. The trypsinized slides were stained with $20 \%$ Giemsa solution for 30 minutes. The numbering of the chromosomes was according to ISCNDA (1989 and 1990), and G-bands was according to Mensher (1987).

-Fluorescent in situ Hybridization (FISH)

FISH technique was carried out according to Iannuzzi et al. (2013) with some modifications. 


\section{Extraction and purification of genomic DNA}

The DNA was extracted using the Qiagen Blood and Tissue Kit (cat No. 69506) according to the manufacturer's instructions.

\section{Probes preparation}

Total genomic DNA from the blood samples was used as a template to amplify the desired DNA fragments using specific primer pairs. The PCR products were then employed to prepare the probes by labeling using the DIG-NickTranslation Kit as described by Fujiwara et al. (2007) with some modifications.

Two subtelomeric SSR primer pairs were employed for sheep. In addition, two primer pairs related to the SPRN (gene coding for Shadow of Prion Protein) were used only for sheep. The sequences of the forward and reverse primer pairs were adopted from Vaiman et al. (2000) and Lampo et al. (2007) as shown in Table (1).

\section{Labeling of probes}

PCR products of subtelomeric SSRs and specific gene (SPRN) fragments were labelled using the DIG-Nick Translation Mix Kit (Roche, cat No. 11745816 910) according to the manufacturer's instructions with minor modifications.

\section{Denaturation and hybridization}

The labeled probes were precipitated with ethanol. A probe stock solution was prepared by suspending in hybridization solution. The tubes were incubated for $15 \mathrm{~min}$ at $37^{\circ} \mathrm{C}$ with occasional vortexing until the precipitated DNA dissolved. Then, the probe was diluted from the stock solution to the desired concentration $(2 \mathrm{ng} / \mu \mathrm{l})$ in hybridization solution.

A volume of $20-30 \mu$ diluted probe was added to the slide, covered with a cover slip $(24 \times 50 \mathrm{~mm})$ and sealed with rubber cement. The slides were placed on a hotplate at $80^{\circ} \mathrm{C}$ for $5 \mathrm{~min}$ to denaturize the probe. The slides were hybridized in a moist chamber at $37^{\circ} \mathrm{C}$ overnight. The slides hybridized with subtelomeric SSR probes were washed 3 times for $5 \mathrm{~min}$ at $37^{\circ} \mathrm{C}$ with $2 \times \mathrm{SSC}$ containing $60 \%$ formamide, followed by one time for 5 min with the immunological detection buffer. While, the slides hybridized with the specific (SPRN) probes were washed 3 times for $5 \mathrm{~min}$ at $45^{\circ} \mathrm{C}$ with $2 \times \mathrm{SSC}$ containing $50 \%$ formamide, followed by 5 times for 2 min with $2 \times \mathrm{SSC}$ and one time for 5 min with the detection buffer.

\section{Detection of signals}

Hybridization signals were detected using the Anti-Digoxigenin-Rhodamine, Fab fragments Kit (Roche, cat No 11207750910) according to its manual instructions. Stained with $20 \mu \mathrm{l}$ of DAPI (4,6-diamidino- 2-phenylindole) counter stain.

\section{Microscopic examination karyotyping, idiograming and signals imaging}

Chromosomes examination and signals imaging were performed using a vertical fluorescence microscope (Leica DM2500) equipped with a cooled monochrome digital camera (Leica DFC340FX). Twenty cells with clearly observable and well spread chromosomes of each male and female sheep were examined and photographed at $100 \times$ magnification under oil immersion. Chromosome counting and karyotyping were performed using the automated karyotyping \& FISH software processing (Leica CW4000) system. Idiograms were constructed from complete chromosomes which showed the maximum possible banding patterns in at least ten different metaphase plates.

Hybridization signals were photographed twice at $100 \times$ magnification under oil immersion, first using a blue filter for DAPI and second using a red filter for rhodamine. Thus, chromosome bands showed up in blue after approximately $300 \mathrm{~nm}$ exposure, and probes showed up in red and were exposed for approximately 10 seconds. For each probe, eight to ten metaphases were photographed and images were overlapped using automated karyotyping \& FISH software processing (Leica CW4000) system.

\section{Results and Discussion:- \\ -Karyotype analyses}

In the present investigation the karyotype of the three sheep breeds (Barki, Rahmani and Ossimi) were first investigated to assess their correspondence to the standard karyotype of sheep. 


\section{Unbanded chromosomes morphological analysis}

The three Egyptian breeds of sheep (Barki, Rahmani and Ossimi) belong to the species (Ovis aries). This species is characterized by a diploid chromosome number of 54 (Hansen, 1973; Ford et al., 1980; Ansari et al., 1996 and Di Meo et al., 2005). The karyotype is composed of 26 autosomal chromosome pairs. Out of these, 3 pairs are metacentric while, 23 pairs are acrocentric (Ahmad and Khan, 2007; Ali et al., 2011 and Pinthon and Pomthong, 2011). While, some discrepancies about the type of the $X$ and $Y$ chromosomes were reported in the literature (Makino et al., 1967; Hansen, 1973; Di Meo et al., 2005; Ali et al., 2011 and Arslan and Zima, 2011).

In the present investigation the karyotype was based on the analysis of twenty well spread metaphase cells of each male and female sheep (Fig. 1). The relative length (RL \%), centromeric index (CI \%) and centromere position were estimated as displayed in Table (2).

In general, the morphological features of the chromosome complement of the three sheep breeds were in accordance with the basic sheep karyotype revealing the karyotype formula $2 \mathrm{n}=54=\mathrm{L}_{6}^{\mathrm{m}}+\mathrm{M}^{\mathrm{a}}{ }_{22}+\mathrm{S}_{24}^{\mathrm{a}}+$ sex chromosomes. For each chromosome pair, slight differences in the measured parameters were detected among the three breeds as shown in Table (2), and illustrated in the histograms (Figs. 2 and 3).

The relative length of the 26 autosomal chromosomes across the three breeds ranged from $8.31 \%$ (for chromosome 1) to $1.95 \%$ (for chromosome 26). The relative length of the longest chromosome (chromosome 1) in Barki, Rahmani and Ossimi breeds was 8.33, 8.31 and $8.33 \%$, respectively. While, the shortest autosomal chromosome (chromosome 26) revealed a relative length of 1.95, 1.96 and 1.97\% in Barki, Rahmani and Ossimi, respectively. Similarly, the three breeds revealed negligible differences in the relative length of the $X(4.44,4.46$ and $4.47 \%)$ and Y $(1.43,1.43$ and 1.47\%) chromosomes in Barki, Rahmani and Ossimi sheep breeds, respectively. These slight differences could be attributed to different levels of chromosome condensation among the three breeds. These results are in agreement with Ansari et al. (1996) and Di Meo et al. (2005).

The centromeric indices for the chromosomes of the three sheep breeds are presented in Table (2) and illustrated as histogram in (Fig.3). The results confirmed the metacentric nature of the three longest chromosomes. The centromeric index for the longest chromosome (chromosome1) was 47.7, 45.7 and 45.4\% in Barki, Rahmani and Ossimi breeds, respectively. While, this index was $45.5,46.3$ and 45.5 for chromosome 2 and $48.6,48.1$ and 47.4 for chromosome 3 in the three breeds. The rest of the autosomes were acrocentric with $0.0 \%$ centromeric index in the three breeds. In addition, the X chromosome proved to be submetacentric with CI\% of 30.3, 29.4 and $29.8 \%$ for Barki, Rahmani and Ossimi breeds, respectively and the $\mathrm{Y}$ chromosome was acrocentric.

These findings are in agreement with several investigations (Makino et al., 1967; Hansen, 1973 and Di Meo et al., 2005). While, Melander (1959) mentioned that the Y chromosome has a median centromere. In addition, Ali $\boldsymbol{e t} \boldsymbol{a l}$. (2011) reported that in Lohi sheep breed, the $X$ chromosome was the largest sub-acrocentric with minute $p$ arm extensions, whereas the $\mathrm{Y}$ chromosome was observed as an asterisk-shaped metacentric. Moreover, Arslan and Zima (2011) reported that in Konya wild sheep, the $\mathrm{X}$ chromosome was the longest acrocentric with a distinct short arm, whereas the $\mathrm{Y}$ chromosome was the smallest element and metacentric.

This examination of the three Egyptian sheep breeds revealed that the fundamental number (NF, number of chromosome arms) of the sheep was $\mathrm{NFa}=58$ for the autosomal chromosomes while, the total was $\mathrm{NF}=61$ in the male and $\mathrm{NF}=62$ in the female. Similar $\mathrm{NFa}$ value of the sheep autosomal chromosomes $(\mathrm{NFa}=58)$ was reported by Arslan and Zima (2011). In this respect, Arslan and Zima (2011) reported that, the family Bovidae includes several species demonstrating variable diploid chromosome numbers but having similar fundamental numbers $(\mathrm{NF}=60)$, which, with the exception of a few cases, vary between 58 and 62 . The karyotype contains variable numbers of centric fusions, or Robertsonian translocations, which have changed the diploid number but not the NF. The variation in the morphology of the sex chromosomes between the present study and the findings reported by Nicodemo et al. (2008), Xing-tang et al. (2008) and Pinthong and Pomthong (2011), could be attributed to the different origin of the studied animals and/or structural chromosomal rearrangements.

GTG-banding analysis

Cytological examination of the G-banded chromosomes for the three Egyptian sheep breeds (Barki, Rahmani and Ossimi) revealed that the karyotype macrostructures were highly conserved and in general, in considerable 
accordance to the standard karyotype of the sheep (Ovis aries) presented by Mensher (1987) and published by the Committee for Standardized Karyotype of Ovis aries (1985).

The G-banding method using the photolytic enzyme trypsin affects the interaction that stabilises the structure of different proteins and nucleic acid components of the chromatin. Therefore, the G-band mechanism is based mainly upon differences in protein composition and organization (Holmquit, 1988 and Ali et al., 2011). It has also been suggested that trypsin treatment leads to the unfolding of protein loops and permits the protein structure associated with the alignment of AT-rich sequences, as reported by Popescu et al. (2000).

The results obtained by Ali et al. (2011) on Lohi sheep were highly inconsistent regarding standard trypsin exposure time for the satisfactory induction of G-bands, which made precise identification of individual chromosomal bands challenging. According to Wiscovitch et al. (1974) and Zhuang et al. (2006) this may have been due to relative humidity, room temperature, and the variable extent of slide maturity during overnight incubation. Therefore, in the present study the optimization of trypsinisation was conducted. The concentration and time for trypsin treatment was ( $0.025 \%$ trypsin EDTA) and (5 to 10 seconds) at $37^{\circ} \mathrm{C}$. This facilitated the accurate identification of individual chromosomal bands.

Moreover, examination of the G-banded metaphase cells revealed variation in the number of bands in each chromosome depending on the degree of the chromosome contraction. Therefore, the analysis of G-banding has been conducted on early metaphase chromosomes as they displayed the highest number of G-bands and thus had the greatest utility for detailed comparative analysis.

The G-band idiogram of the chromosomes was developed based on twenty selected metaphases using automated karyotyping \& FISH software processing (Leica CW4000).

GTG- banding karyotype of sheep (Ovis aries) confirmed that, the chromosome diploid number was 54 ( $2 \mathrm{n}=54, \mathrm{XX}$ $/ \mathrm{XY}$ ) and the karyotype formula was $2 \mathrm{n}=54=\mathrm{L}^{\mathrm{m}}{ }_{6}+\mathrm{M}^{\mathrm{a}}{ }_{22}+\mathrm{S}_{24}^{\mathrm{a}}+$ sex chromosomes (Figs. 4 and 5). The G- banded idiogram of each of the three Egyptian sheep breeds consisted of 345 bands in one set of haploid chromosome complement, including sex chromosomes. The number of G-positive (heterochromatic) bands was 159, whereas the total number of G-negative (euchromatic) bands was 186 (Table 3).

At the cytogenetic level, the identification of chromosomes 4, 5 and 6 was difficult, due to their indistinct band organization. Similarly, chromosomes 8,9 and 10 were often difficult to differentiate. The precise identification of chromosomes 19 to 26 also required great care due to their small size. These results are in agreement with Ansari $\boldsymbol{e t}$ al. (1999), Lopez and Arruga (1996) and Stone and Stephens (1993).

The G- banded idiogram of the three Egyptian sheep breeds could be identified as four chromosomal groups.

The first group was consisted of three large metacentric pairs, chromosomes no. 1, 2, and 3. In this group the Gbanding pattern revealed three arms (1p, 1q and 2q) with two regions, while, in the other three arms (2p, 3p and 3q) the G-bands constituted one region. The number of bands in the chromosomes 1, 2 and 3 was 30, 34 and 26, respectively. The percentage of band length to the total length of the chromosome ranged from 1.3 for the dark band $1 \mathrm{q} 21$ to 15.87 for the light band 3p13. While, the relative lengths of these three chromosomes to the chromosome complement were $9.8,9.32$ and 7.81 for chromosome 1,2, and 3, respectively.

The second group was consisted of eleven medium acrocentric pairs, from chromosome no. (4) to chromosome no. (14). The G-banding pattern of these eleven chromosomes was comprised of one region. Fifteen bands were observed in the three chromosomes no. 4, 5 and 8, thirteen bands were detected in the chromosomes no. 11 and 13, and also twelve bands were observed in the chromosomes no. 7 and 9. While, the number of bands in the four chromosomes no. 6,10,12 and 14 were $14,11,10$ and 9, respectively. The percentage of band length to the total length of the chromosome ranged from 1.43 observed as a light band in chromosome 4 (4q111) to 25.00 for the light band $9 \mathrm{q} 13$. While, the relative length of this group of chromosomes ranged from 3.0 for chromosome 14 to 4.0 for chromosome 4.

The third group was consisted of twelve small acrocentric pairs, from chromosome no. (15) to chromosome no. (26), where all the bands were in one region. Eleven bands were detected in two chromosomes no. 15 and 17, nine bands 
were observed in the five chromosomes no. 16, 18, 20, 24, and 25, seven bands were observed in two chromosomes no. 19 and 21, and five bands were observed in two chromosomes no. 22 and 26. While, six bands were detected in the chromosome no. 23. The percentage of band length to the total length of the chromosome ranged from 2.86 for the light band observed in chromosome 20 (20q17) to 27.27 for the dark band in chromosome 22 (22q12). While, the relative length of this group of chromosomes ranged from 2.02 for chromosome 26 to 2.89 for chromosome 15 .

The fourth group comprised the two sex chromosomes (X and Y). The X chromosome was submetacentric where the long arm (q) was divided into two G-banded regions, while, the short arm had one region. The short arm comprised three bands, while, in the long arm, eleven bands were present in the two regions. The percentage of band length to the total length of the chromosome X ranged from 1.96 for the light band (Xq13) to 57.89 for the dark band (Xp12). The acrocentric Y chromosome comprised five bands represented in one region. The percentage of band length to the total length of the chromosome Y ranged from 12.50 for the light band (Yq15) to 31.25 for the light band (Yq11). While, the relative lengths of the $\mathrm{X}$ and $\mathrm{Y}$ chromosomes were 5.42 and 1.43, respectively.

\section{Fluorescent in Situ Hybridization (FISH) analysis}

Molecular techniques including Fluorescent in Situ Hybridization (FISH) have been used for chromosome studies and breed characterization in several mammalian species such as river buffalo, cattle, sheep and goat (Pauciullo $\boldsymbol{e t}$ al., 2014, Di Meo et al., 2007 and Iannuzzi et al., 2013). This technique enables the physical localization of one or more probes along the chromosomes with high accuracy.

In the present investigation two subtelomeric microsatellite probes (EPCDV008 and EPCDV016) and two specific SPRN related probes (OriaBAC273H7 and OriaBAC265G4) were hybridized to the metaphase chromosomes. The use of DAPI-stained chromosomes with the rhodamine-labeled probes was useful to accurately assigning each of the probes to its cytological location. Polymorphic hybridization sites were observed among the investigated breeds.

In chromosome spreads with telomeric signals, two signals were visible with TRITC -filter as two spots at both ends of each chromosome, regardless of the age of the slides. However, there were variations in signal intensities among chromosomes, which appeared to be random.

Across the three sheep breeds, the four probes hybridized to a total of nine different loci in seven autosomal chromosomes (No. 1, 2, 4, 17, 20, 22 and 24) (Table 3).

Microsatellites subtelomeric probes (EPCDV008 and EPCDV016) hybridized to six different loci distributed in five chromosomes (No. 1, 2, 4, 17 and 24). Five loci were located in the subtelomeric region of chromosomes (No. 1, 2, 17 and 24). While, only one non-subtelomeric locus was hybridized with EPCDV016 in Rahmani sheep. This was located on chromosome No.4 (4q22) as an interstitial band.

The EPCDV008 probe hybridized to the short arm (p) of chromosomes No.1 in Barki and Rahmani breeds (1p37 and 1p36) (Fig. 6) and to chromosome No.17 (17q26) (Fig.6) in the Ossimi breed. These three loci were reported by Vaiman et al. (2000) for the same probe in sheep. While, the EPCDV016 probe revealed three different loci, two subtelomeric loci in Barki and Ossimi (2q45 and 24q24) (Fig.7), and a unique interstitial band on chromosome No.4 (4q22) (Fig.7) in Rahmani. These results are in good agreement with Vaiman et al. (2000). Therefore, the results proved that the two microsatellites subtelomeric probes (EPCDV008 and EPCDV016) were successful in differentiating among the three breeds.

In situ hybridization of the specific SPRN related probes (OriaBAC273H7 and OriaBAC265G4) with the three sheep breeds revealed three different loci on three small acrocentric chromosomes (No. 17, 20 and 22). The signals were visible as two spots on each chromosome, except in the sheep Barki where only one spot was detected per chromosome. Similarly, Sera et al. (1995) found one spot at each end of the chromosome when hybridizing the sheep chromosomes with the telomeric (TTAGGG) sequence. The probe OriaBAC273H7 hybridized to a similar locus (20q13) in breeds Rahmani and Ossimi (Fig.8), while, in Barki, it hybridized to a different locus (22q24) (Fig.8). However, probe OriaBAC265G4 hybridized to three different loci $(17 q 25,22 q 24$ and 20q13) in Barki, Rahmani and Ossimi, (Fig.9).

This demonstrates that the probe OriaBAC265G4 was successful in differentiating among the three breeds, while, OriaBAC273H7 was only successful in characterizing the Barki breed. In this context Lampo et al. (2007) localized 
the two probes (OriaBAC273H7 and OriaBAC265G4) on the 22q24 locus in sheep. Therefore, the present results are not in complete accordance with those of Lampo et al. (2007). This could be attributed to the different breeds investigated in both studies.

The present results assured that the FISH-mapping technique is a powerful tool in cytogenetic investigations. In this context, FISH has been reported previously as the best and fast method to (a) physically map loci in specific chromosome regions (Di Meo et al., 2007 and Goldammer et al., 2009), (b) identify correctly chromosomes and chromosome regions involved in chromosome abnormalities (Iannuzzi et al., 2001a and Molteni et al., 2007), (c) anchor radiation hybrid maps to specific chromosome regions (Perucatti et al., 2009) and (d) clarify the chromosome evolution of species by analyzing the gene order among homologous chromosomes of species (Iannuzzi et al., 2009).

It is worth noting that the variation observed in FISH analysis among the three sheep breeds could be due to their different origin and / or the occurrence of rearrangements in their genomes. The sheep Barki breed originated in North Africa in the Coastal Mediterranean Zone. While, the origin of the Ossimi breed is Giza and it is the most popular among the Nile Valley and Delta breeds. Rahmani originated in Northern Syria and Southern Turkey and was introduced into Egypt in the $19^{\text {th }}$ century (El Shennawy, 1995).

In conclusion, in the present cytogenetic study the first standard karyotype for the three main Egyptian sheep breeds was established by GTG-banding. In addition, the results revealed the adequacy of the FISH technique for physically mapping two subtelomeric and two specific SPRN related loci to the Egyptian sheep breed chromosomes. All hybridization signals were different, indicating high specificity and reproducibility of the technique used and at the same time proving that these subtelomeric and specific SPRN related loci are suitable markers for accurate identification of Egyptian breed chromosomes or specific regions within them.

Table 1:-Names, nucleotide sequences of the primer pairs and annealing temperature (Ta) used for probes preparation.

\begin{tabular}{|c|c|c|c|c|c|}
\hline Primer type & Primer name & Forward sequence & Reverse sequence & $\mathrm{Ta}\left({ }^{\circ} \mathrm{C}\right)$ & Reference \\
\hline \multirow[t]{2}{*}{$\begin{array}{l}\text { Subtelomeric } \\
\text { SSR primers }\end{array}$} & EPCDV008 & $\begin{array}{lll}\text { GAC } & \text { TTT } & \text { CCA } \\
\text { AGA } & \text { GCT } & \text { AAG } \\
\text { CG (20) } & \\
\end{array}$ & $\begin{array}{l}\text { GAT CTC CTC } \\
\text { TAA GCT CAC AC } \\
(20)\end{array}$ & $58^{\circ} \mathrm{C}$ & $\begin{array}{l}\text { Vaiman et al. } \\
\text { (2000) }\end{array}$ \\
\hline & EPCDV0016 & $\begin{array}{lll}\text { CTT } & \text { CCC } & \text { GTT } \\
\text { CAT } & \text { GCA } & \text { TTC } \\
\text { TTG }(21) & \\
\end{array}$ & $\begin{array}{lrr}\text { GAG } & \text { TGT } & \text { GGT } \\
\text { ATC } & \text { TAA } & \text { TCC } \\
\text { AGC (21) } & \\
\end{array}$ & $58^{\circ} \mathrm{C}$ & \\
\hline \multirow[t]{2}{*}{$\begin{array}{l}\text { Specific } \\
(\mathrm{SPRN}) \text { related } \\
\text { primers }\end{array}$} & OriaBAC273H7 & $\begin{array}{l}\text { GGG ACC ATC } \\
\text { CTG CTG TGA CG } \\
(20)\end{array}$ & $\begin{array}{lll}\text { TCC ACT } & \text { GTC } \\
\text { TGC GTC } & \text { GTC } \\
\text { CTC (21) } & \\
\end{array}$ & $65^{\circ} \mathrm{C}$ & $\begin{array}{l}\text { Lampo et al. } \\
\text { (2007) }\end{array}$ \\
\hline & OriaBAC265G4 & $\begin{array}{lll}\text { TGA } & \text { GAG } & \text { GTA } \\
\text { AGA } & \text { AGA } & \text { CCA } \\
\text { CCA AA }(23) & \end{array}$ & $\begin{array}{lll}\text { TCA } & \text { ACC } & \text { GCA } \\
\text { GAA } & \text { CTA } & \text { TGA } \\
\text { ACC }(21) & \end{array}$ & $63{ }^{\circ} \mathrm{C}$ & \\
\hline
\end{tabular}


Table 2:-Relative length (RL \%), centromeric index (CI \%) and centromere position (CP) of each chromosome for the three sheep breeds (Barki, Rahmani and Ossimi).

\begin{tabular}{|c|c|c|c|c|c|c|c|}
\hline \multirow{2}{*}{$\begin{array}{c}\text { Chr. } \\
\text { No. }\end{array}$} & \multicolumn{3}{|c|}{$\begin{array}{c}\text { Relative length (RL \%) of } \\
\text { the chromosomes }\end{array}$} & \multicolumn{3}{c|}{ Centromeric index (CI \%) of the } & \multirow{2}{*}{$\begin{array}{c}\text { Centromere } \\
\text { position } \\
\end{array}$} \\
\cline { 2 - 7 } & Barki & Rahmani & Ossimi & Barki & Rahmani & Ossimi & (CP) \\
\hline 1 & 8.33 & 8.31 & 8.33 & 47.7 & 45.7 & 45.4 & metacentric \\
\hline 2 & 7.57 & 7.47 & 7.43 & 45.5 & 46.3 & 45.5 & metacentric \\
\hline 3 & 7.20 & 7.16 & 7.20 & 48.6 & 48.1 & 47.4 & metacentric \\
\hline 4 & 4.56 & 4.54 & 4.53 & 0.0 & 0.0 & 0.0 & acrocentric \\
\hline 5 & 4.26 & 4.26 & 4.20 & 0.0 & 0.0 & 0.0 & acrocentric \\
\hline 6 & 3.96 & 4.06 & 3.99 & 0.0 & 0.0 & 0.0 & acrocentric \\
\hline 7 & 3.84 & 3.85 & 3.87 & 0.0 & 0.0 & 0.0 & acrocentric \\
\hline 8 & 3.77 & 3.75 & 3.76 & 0.0 & 0.0 & 0.0 & acrocentric \\
\hline 9 & 3.60 & 3.65 & 3.60 & 0.0 & 0.0 & 0.0 & acrocentric \\
\hline 10 & 3.53 & 3.53 & 3.54 & 0.0 & 0.0 & 0.0 & acrocentric \\
\hline 11 & 3.44 & 3.46 & 3.42 & 0.0 & 0.0 & 0.0 & acrocentric \\
\hline 12 & 3.34 & 3.36 & 3.39 & 0.0 & 0.0 & 0.0 & acrocentric \\
\hline 13 & 3.31 & 3.30 & 3.29 & 0.0 & 0.0 & 0.0 & acrocentric \\
\hline 14 & 3.14 & 3.16 & 3.16 & 0.0 & 0.0 & 0.0 & acrocentric \\
\hline 15 & 3.00 & 3.02 & 3.04 & 0.0 & 0.0 & 0.0 & acrocentric \\
\hline 16 & 2.97 & 2.93 & 2.95 & 0.0 & 0.0 & 0.0 & acrocentric \\
\hline 17 & 2.88 & 2.83 & 2.89 & 0.0 & 0.0 & 0.0 & acrocentric \\
\hline 18 & 2.81 & 2.71 & 2.78 & 0.0 & 0.0 & 0.0 & acrocentric \\
\hline 19 & 2.66 & 2.61 & 2.68 & 0.0 & 0.0 & 0.0 & acrocentric \\
\hline 20 & 2.58 & 2.52 & 2.57 & 0.0 & 0.0 & 0.0 & acrocentric \\
\hline 21 & 2.46 & 2.46 & 2.49 & 0.0 & 0.0 & 0.0 & acrocentric \\
\hline 22 & 2.41 & 2.40 & 2.39 & 0.0 & 0.0 & 0.0 & acrocentric \\
\hline 23 & 2.32 & 2.32 & 2.34 & 0.0 & 0.0 & 0.0 & acrocentric \\
\hline 24 & 2.17 & 2.19 & 2.21 & 0.0 & 0.0 & 0.0 & acrocentric \\
\hline 25 & 2.08 & 2.10 & 2.09 & 0.0 & 0.0 & 0.0 & acrocentric \\
\hline 26 & 1.95 & 1.96 & 1.97 & 0.0 & 0.0 & 0.0 & acrocentric \\
\hline $\mathrm{X}$ & 4.44 & 4.46 & 4.47 & 30.3 & 29.4 & 29.8 & submetacentric \\
\hline $\mathrm{Y}$ & 1.43 & 1.43 & 1.47 & 0.0 & 0.0 & 0.0 & acrocentric \\
\hline & & & & & & & \\
\hline
\end{tabular}

Table 3:-Subtelomeric SSR probes, specific SPRN related probes and their hybridized loci in the chromosomes of the three sheep breeds.

\begin{tabular}{|c|c|c|c|c|c|}
\hline Probe type & Probe name & \multicolumn{3}{|c|}{ Loci in } & Loci in references \\
\cline { 2 - 5 } & EPCDV008 & $1 \mathrm{p} 37$ & $1 \mathrm{p} 36$ & $17 \mathrm{q} 26$ & $\begin{array}{c}\text { 1p36-37 and 17q26 } \\
\text { (Vaiman } \text { et al., 2000) }\end{array}$ \\
\hline \multirow{2}{*}{$\begin{array}{c}\text { Subtelomeric SSR } \\
\text { probes }\end{array}$} & EPCDV016 & $2 \mathrm{q} 45$ & $4 \mathrm{q} 22^{*}$ & $24 \mathrm{q} 24$ & $\begin{array}{c}\text { 2q45, 24q24 and 4q22 } \\
\text { (Vaiman } \text { et al., 2000) }\end{array}$ \\
\cline { 2 - 5 } & OriaBAC273H7 & $22 \mathrm{q} 24$ & $20 \mathrm{q} 13$ & $20 \mathrm{q} 13$ & 22q24 (Lampo et al,. \\
\cline { 2 - 5 } $\begin{array}{c}\text { Specific SPRN } \\
\text { related probes }\end{array}$ & OriaBAC265G4 & $17 \mathrm{q} 25$ & $22 \mathrm{q} 24$ & $20 \mathrm{q} 13$ & 2007) \\
\hline
\end{tabular}

* Nontelomeric locus 


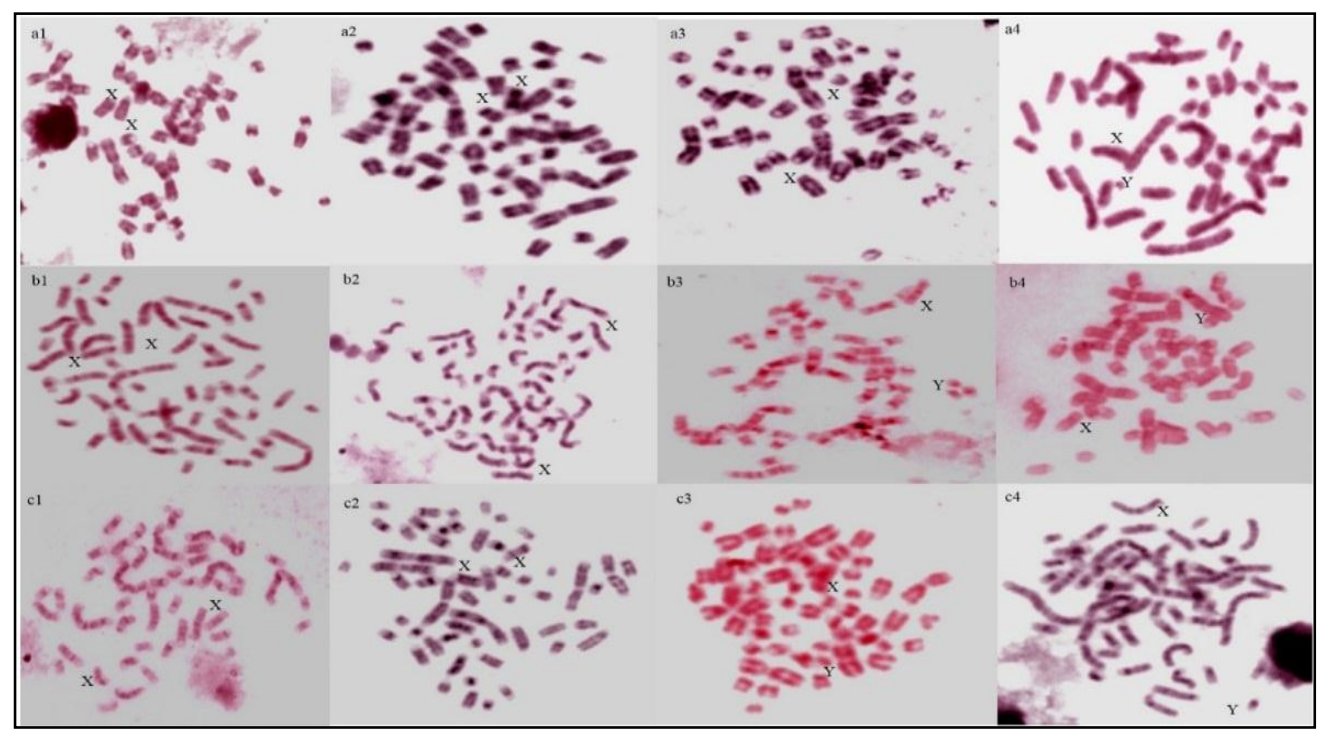

Fig. 1:-Spread metaphase cells of male and female for the three sheep, (a1, a2 and a3) female Barki, (a4) male Barki, (b1and b2) female Rahmani, (b3and b4) male Rahmani, (c1and c2) female Ossimi and (c3and c4) male Ossimi.

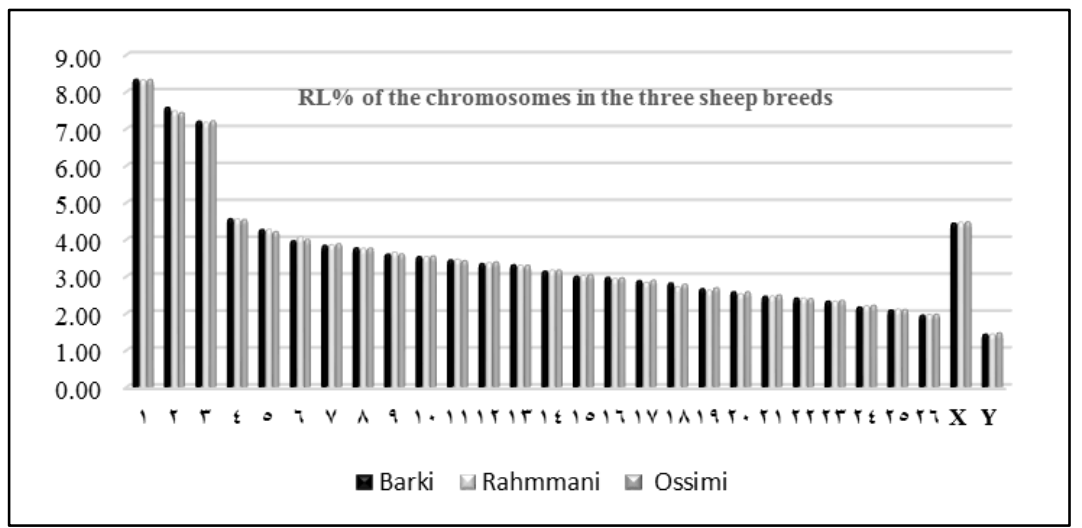

Fig.2:-Histogram showing the relative length (RL \%) of the 26 autosomal pairs and the $\mathrm{X}$ and $\mathrm{Y}$ chromosomes in the three sheep breeds (Barki, Rahmani and Ossimi).

\section{C.I \% of the three sheep breeds}

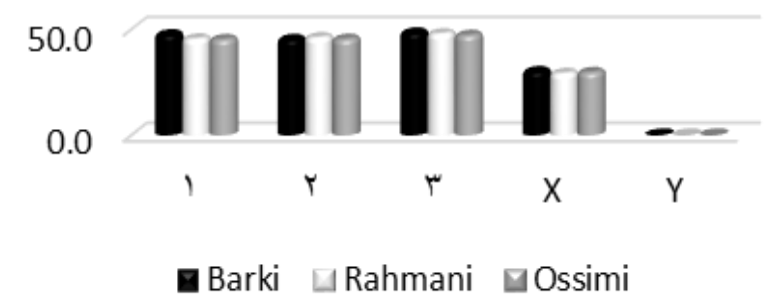

Fig 3:-Histogram showing the centromeric index (CI \%) of the three sheep breeds: Barki, Rahmani and Ossimi for the chromosomes 1, 2, 3, X and Y. 


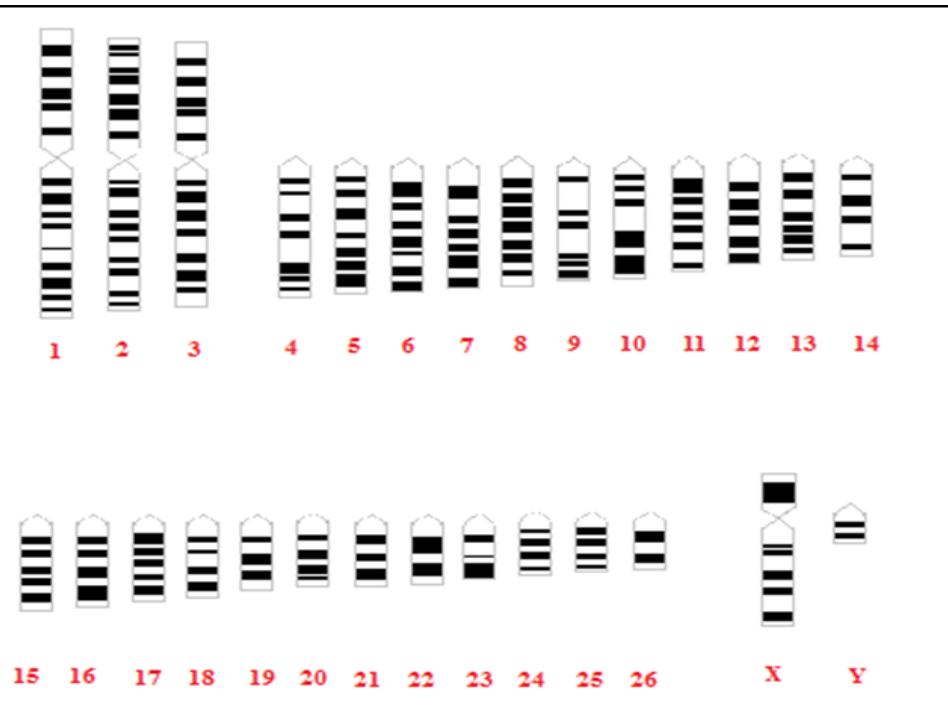

Fig 4:-Idiogram of sheep (Ovis aries) $2 \mathrm{n}=54$ as revealed by the Gbanding technique.

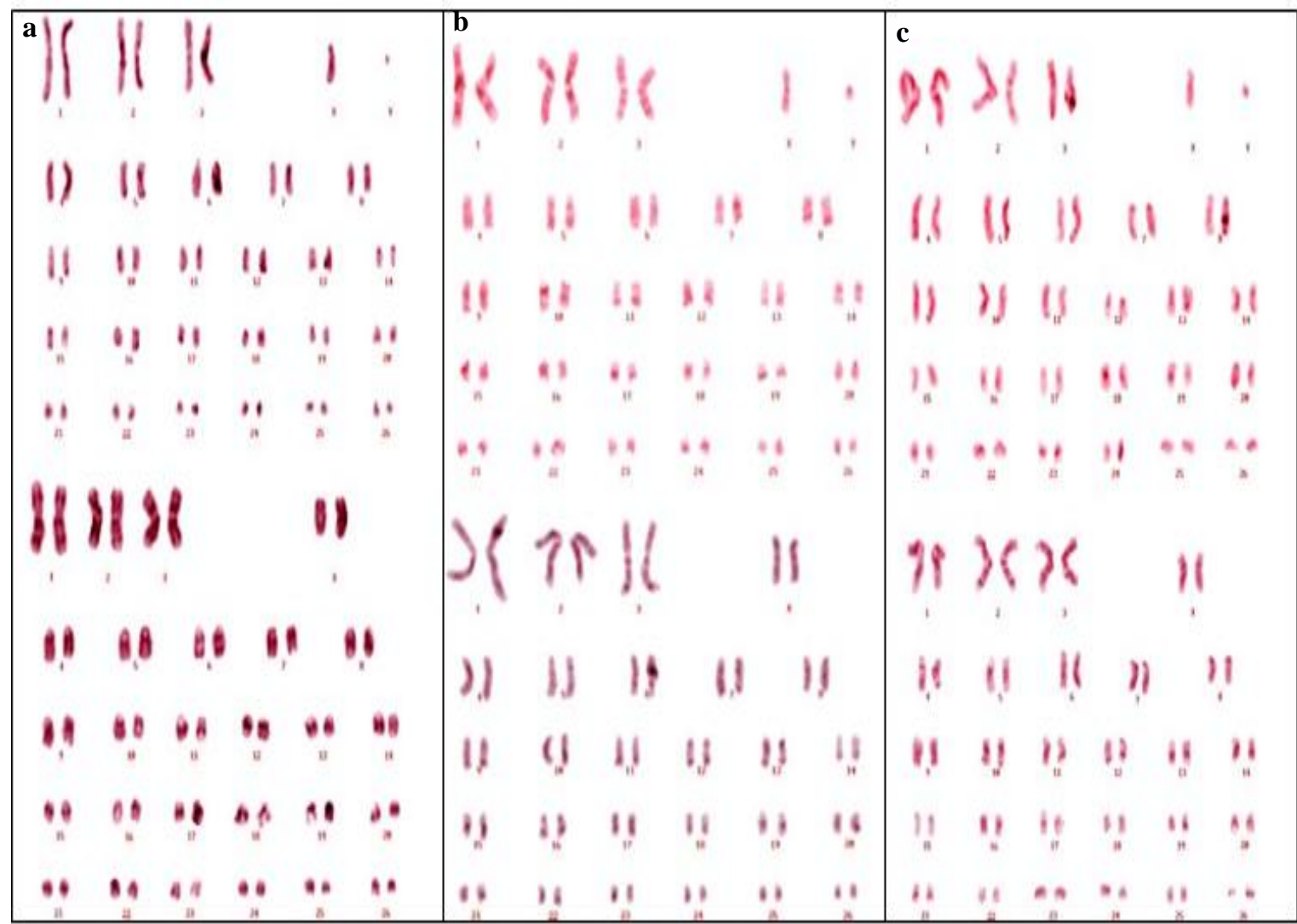

Fig 5:-GTG-banding karyotype of male and female of Barki, Rahmani and Ossimi breeds ( $a, b$ and c) respectively. 

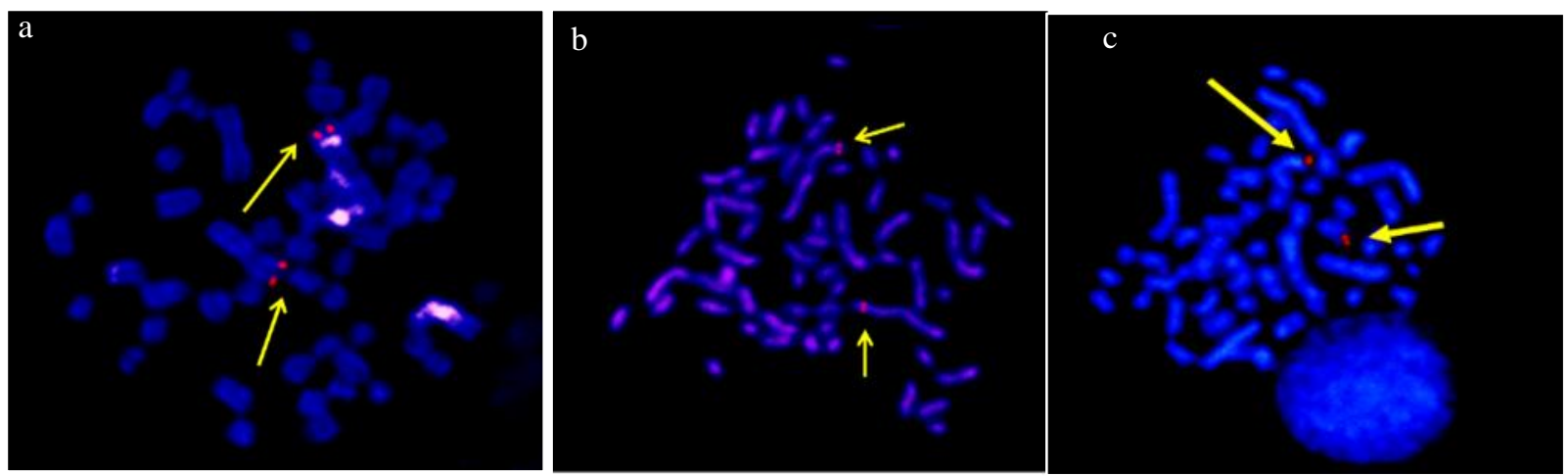

Fig 6:-FISH-mapping of subtelomeric SSR Dig-probe (EPCDV008) with the sheep breeds. (a) Barki, in locus (1p37). (b) Rahmani in locus (1p36). (c) Ossimi, in locus (17q26) with metaphase with mixed filter.

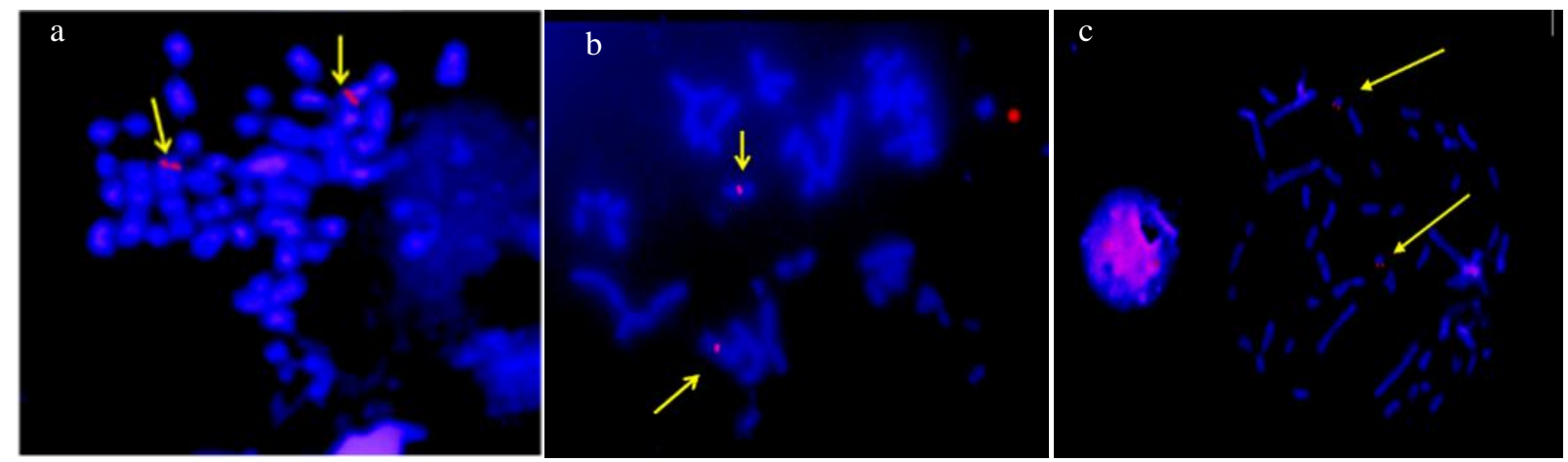

Fig7:-FISH-mapping of subtelomeric SSR Dig-probe (EPCDV016) with the sheep breeds. (a) Barki, in locus (2q45). (b) Rahmani , in locus (4q22). (c) Ossimi, in locus (24q24) with metaphase with mixed filter.

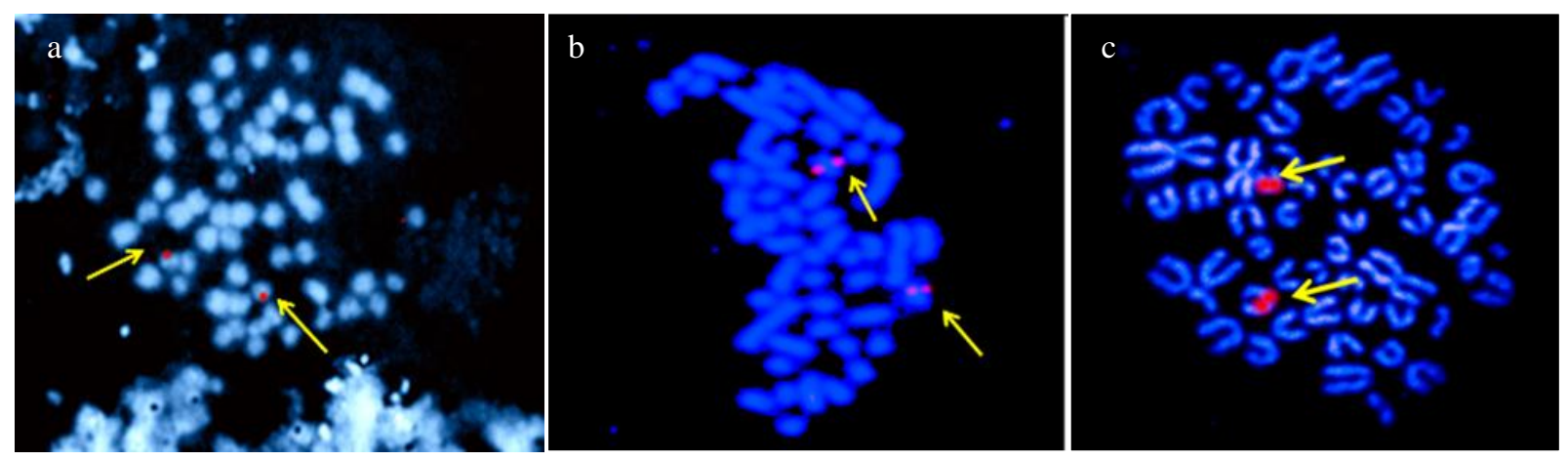

Fig 8:-FISH-mapping of the specific SPRN related Dig-probe (BAC273H7) with the sheep breeds. (a) Barki, in locus (22q24). (b) Rahmani, in locus (20q13). (c) Ossimi, in locus (20q13) with metaphase with mixed filter.
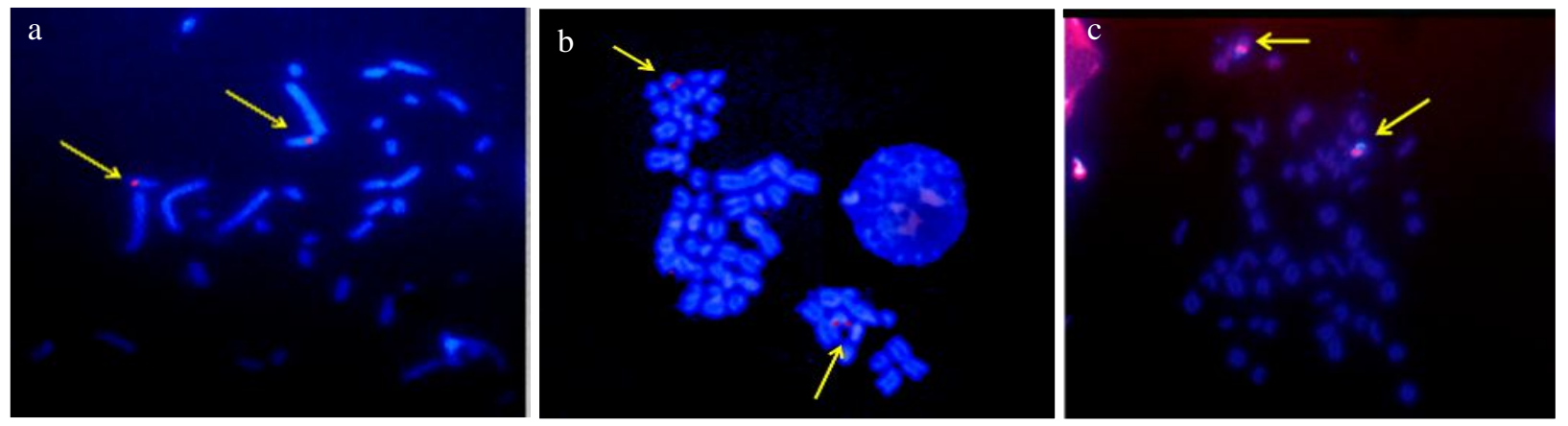

Fig.9:-FISH-mapping of the specific SPRN related Dig-probe (BAC265G4) with the sheep breeds (a) Barki, in locus (17q25). (b) Rahmani , in locus (22q24).(c) Ossimi, in locus (20q13). with metaphase with mixed filter. 


\section{References:-}

1. Ahmad, S. and Khan, M. S. (2007): Karyology of Kari sheep. Pakistan Vet. J., 27: 118-120.

2. Ali, A.; Babar, M. E.; Mahmood, S. and Imran, M. (2011): First report of GTG-banded nomenclature of Pakistani Lohi sheep (Ovis aries). Turk. J. Vet. Anim. Sci., 35: 213-217.

3. Ansari, H. A.; Bosma, A. A.; Broad, T. E.; Bunch, T. D.; Long, S. E.; Maher, D. W.; Pearce, P. D. and Popescu, C.P. (1999): Standard G-, Q- and R-banded ideograms of the domestic sheep (Ovis aries): homology with cattle (Bos taurus). Cytogenet.Cell Genet., 85:317-324.

4. Ansari, H. A.; Maher, D. W.; Pearce, P. D. and Broad, T. E. (1996): Resolving ambiguities in the karyotype of domestic sheep (Ovis aries) II. G-, Q-, and R-banded idiograms, and chromosome- specific molecular markers. Chromosoma, 105:62-67.

5. Arslan, A. and Zima, J. (2011): Banded karyotype of the Konya wild sheep (Ovis orientalis anatolica Valenciennes, 1856) from Turkey. Comp Cytogenet., 5: 81-89.

6. Chaiyasut, K. (1989): Cytogenetics and Cytotaxonomy of the Family Zephyranthes. Department of Botany, Faculty of Science, Chulalongkorn University, Bangkok, Thailand.Pp.119-178

7. Committee for Standardized Karyotype of Ovis aries (1985): Standard nomenclature for the G-band karyotype of the domestic sheep (Ovis aries). Hered., 103: 165-170.

8. Di Meo, G. P.; Perucatti, A.; Floriot, S.; Hayes, H.; Schibler, L.; Rullo, R.; Incarnato, D.; Ferretti, L.; Cockett, N.; Cribu, E.; Williams, J. L.; Eggen, A. and Iannuzzi, L. (2007): An advanced sheep (Ovis aries, 2n=54) cytogenetic map and assignment of 88 new loci by fluorescent in situ hybridization and $\mathrm{R}$ banding. Anim. Genet., 38:233-240.

9. Di Meo, G. P.; Perucatti, A.; Floriot, S.; Incarnato, D.; Rullo, R.; Jambrenghi, A. C.; Ferretti, L.; Vonghia, G.; Cribiu, E.; Eggen, A. and Iannuzzi, L. (2005): Chromosome evolution and improved cytogenetic maps of the Y chromosome in cattle, zebu, river buffalo, sheep and goat. Chromosome Res., 13: 349-355.

10. Di Meo, G. P.; Perucatti, A.; Gautier, M.; Hayes, H.; Incarnato, D.; Eggen, A. and Iannuzzi, L. (2003): Chromosome localization of the 31 type Texas bovine markers in sheep and goat chromosomes by comparative FISH-mapping and R-banding. Anim. Genet., 34: 294-296.

11. Ekambaram, B.; Gupta, B. R.; Prakash, M. G.; Sudhaker, K. and Reddy, V. R. (2011): Cytogenetic characterization of Mahabubnagar goats. Amilnadu J. Vet. \& Ani. Sci., 7:157-163

12. El-Shennawy, M. (1995): Sheep development program in Egypt. In: Gabiña D. (ed.). Strategies for Sheep and Goat Breeding.Zaragoza, CIHEAM, pp. 27 -32 Cahiers Options Méditerranéennes; n. 11.

13. Farhadi, A.; Genualdo, V.; Perucatti, A.; Hafezian, S. H.; Rahimi- Mianji, G.; Delorenzi, L.; Parma, P.; Iannuzzi, L. and Iannuzzi, A. (2013):Comparative FISH mapping of BMPR1B, BMP15 and GDF9 fecundity genes on cattle, river buffalo, sheep and goat chromosomes. J. Genet., 92(3):595-597.

14. Ford, C. E.; Pollock, D. L. and Gustavsson, I. (1980): (eds.) Reading Conference. Proceedings of the First International Conference for the Standardisation of Banded Karyotypes of Domestic Animals. Hered., 92, 145162.

15. Fronicke, L. and Wienberg, J. (2001): Comparative chromosome painting defines the high rate of karyotype changes between pigs and bovids. Mamm Genom., 12: 442-449.

16. Fujiwara, A.; Fujiwara, M.; Nishida-Umehara C.; Abe, S. and Masaoka, T. (2007): Characterization of Japanese flounder karyotype by chromosome bandings and fluorescence in situ hybridization with DNA markers. Genet., 131: 267-274.

17. Glowatzki-Mullis, M. L.; Muntwyler, J.; Bäumle, E. and Gaillard, C. (2008): Genetic diversity measures of Swiss goat breeds as decision-making support for conservation policy. Small Rum. Res., 74(1-3):202-211.

18. Goldammer, T.; Di Meo, G. P.; Lühken, G.; Drögemüller, C.; Wu, C. H.; Kijas, J.; Dalrymple, B. P.; Nicholas, F. W.; Maddox, J. F.; Iannuzzi, L. and Cockett, N. E. (2009): Molecular cytogenetics and gene mapping in sheep (Ovis aries, $2 \mathrm{n}=54$ ). Cytogenet. Genom. Res., 126, 63-76.

19. Hansen, K. M. (1973): The karyotype of the domestic sheep (Ovis aries) identified by quinacrine mustard staining and fluorescence microscopy. Hered., 75:233-240.

20. Holmquit, G. (1988): DNA sequences in G-bands and R-bands. In: Chromosomes and Chromatin, Adolph, K.W. (ed.) CRC press, Florida, 2:250 - 276.

21. Iannuzzi, A.; Perucatti, A.; Genualdo, V.; Caputi-Jambrenghi, A.; Peretti, V.; Vonghia, G. and Iannuzzi, L. (2013): Cytogenetic investigations in sheep reared in Southern-Italy by using both chromosome banding and FISH-mapping techniques. Egyp. J. Sheep and Goat Sci., 8: 1-6.

22. Iannuzzi, L.; Di Meo G. P.; Perucatti A.; Schibler L.; Incarnato D. and Cribiu, E. P. (2001b): Comparative FISH mapping in river buffalo and sheep chromosomes: assignment of forty autosomal type I loci from sixteen human chromosomes. Cytogenet. Cell Genet., 94: 43-48. 
23. Iannuzzi, L.; Di Meo, G.P.; Hayes, H.; Perucatti, A.; Incarnato, D.; Gautier, M. and Eggen, A. (2001a): FISHmapping of 31 type I loci (Texas markers) to river buffalo chromosomes. Chrom. Res., 9: 339-342.

24. Iannuzzi, L.; King, W. A. and Di Berardino, D. (2009): Chromosome evolution in domestic bovids as revealed by chromosome banding and FISH-mapping techniques. Cytogenet. Genome Res., 126:49-62.

25. ISCNDA (1989-1990): International System for Cytogenetic Nomenclature of Domestic Animals. (Di Berardino, D.; Hayes, H.; Fries, R. and Long, S.) (eds). Cytogenet Cell Genet., 53: 65-79.

26. Kenthao, A.;Tanomtong, A.; Supanuam, P.; Pinyoteppratan, C.; Muangprom, P.; Buranarom, K. and Sanoamuang, L. (2012): Standardized karyotype and idiogram of mehsani buffaloes Bubalus bubalis by conventional staining, GTG-banding, CBG-banding and AG-NOR-banding techniques. Buffalo Bull., 31(1):239.

27. Lampo, E.; Poucke, M. V; Hugot, K.; Hayes, H.; Zeveren, A. V. and Peelman, L. J. (2007): Characterization of the genomic region containing the Shadow of Prion Protein (SPRN) gene in sheep. BMC Genom., 8:138-148.

28. Larkin, D. M.; Wind, A. E.; Rebeiz, M. et al. (2003): A cattle-human comparative map built with cattle BACends and human genome sequence. Genome Res., 13:1966-1972.

29. Liu, Y. L.; Cheng, M.; Jiang, M. F.; Wang, Y.; Wang, J. and Fu, X. H. (2014): Genetic diversity analysis of eight indigenous goat breeds (groups) in China using AFLP markers. Russ. J. Genet., 50(12):1294-1301.

30. Lopez, C. N. L. and Arruga, M. V. (1996): Induction of fragile sites in goats: A preliminary study. Genet. Sel. Evo., 1.28:129-139.

31. Mahmoudi, B.; Bayat, M.; Sadeghi, R.; Babayev, M. and Abdollahi, H. (2010): Genetic diversity among three goat populations assessed by microsatellite DNA markers in Iran. Glob. Vet., 4(2):118-124.

32. Makino, S.; Shimba, H.; Sofuni, T. and Ikeuchi, T. (1967): A revised study of the chromosomes in the goat and the sheep. Proc. Jap. Acad., 43:913-917.

33. Mekuriaw, G.; Gizaw, S.; Dessie, T.; Mwai, O.; Djikeng, A. and Tesfaye, K. (2016): A review on current knowledge of genetic diversity of domestic goats (Capra hircus) identified by microsatellite loci: How those efforts are strong to support the breeding programs? J. Life Sci. Biomed., 6(2): 22-32.

34. Melander, Y. (1959): The mitotic chromosomes of some cavicorn mammals (Bos taurus L., Bison Bonasus L. and Ovis aries L.). Hered., 45: 649-464.

35. Mensher, S. H. (1987): Comparative Study of Elongated Chromosomes in Sheep and Goats and a Proposed Standard. M.Sc. Thesis, Dept. of Animal, Dairy and Veterinary Sciences, University Logan, Utah State, pp. 57.

36. Molteni, L.; Perucatti, A.; Iannuzzi, A.; Di Meo, G. P.; De Lorenzi, L.; De Giovanni, A.; Incarnato, D.; Succi, G.; Cribiu, E.; Eggen, A. and Iannuzzi, L. (2007): A new case of reciprocal translocation in a young bull: rcp

37. Murphy, W. J.; Pevzner, P. A. and O'Brien, S. J. (2004): Mammalian phylogenomics comes of age. Trends Genet., 20(12): 631-639.

38. Nicodemo, D.; Pauciullo, A.; Castello, A.; Soysal, I.; Aytaç, M. and Di Berardino, D. (2008): A cytogenetic study on the Angora breed of goat (Capra hircus) reared in Turkey. J. Tekirdag Agric. Fac., 5(3)247-252.

39. Othman, E. O.; Hassan, R. D.; Ahmed, A.; Adel E. E. and Mohamed, F. A. (2015): DNA characterization and polymorphism of KISS1 gene in Egyptian small ruminant breeds. African J. of Biot.,14(30):2335-2340.

40. Pauciullo, A.; Perucatti, A.; Cosenza, G.; Iannuzzi, A., Incarnato, D.; Genualdo, V.; Di Berardino, D. and Iannuzzi, L. (2014): Sequential cross-species chromosome painting among river buffalo, cattle, sheep and goat: A useful tool for chromosome abnormalities diagnosis within the family Bovidae. PLoS ONE, 9:110297110304.

41. Perucatti, A.; Di Meo, G. P.; Goldammer, T.; Incarnato, D.; Nicolae, I.; Brunner, R. and Iannuzzi, L.(2009): FISH-mapping comparison between river buffalo chromosome 7 and sheep chromosome 6: assignment of new loci and comparison with HSA4. Cytogenet. Genome Res., 124:106-111.

42. Pinthong, K. and Pomthong, B. (2011): Standardized karyotype and idiogram of Thai native goat, Capra hircus (Artiodactyla, Bovidae) by conventional staining, GTG-banding, CBG-banding and Ag-NOR banding techniques. Koch Cha Sarn J. Sci., 36(2):15-35.

43. Popescu, P.; Hays, H. and Dutrillaux, B. (2000): Techniques in animal cytogenetics: In Chromosome Banding Techniques, INRA (ed.) Springer, Berlin, Heidelberg, pp 251.

44. Sera, C. D.; Chowdhary, B. P. and Gustavsson, I. (1995): Localization of the telomeric (TTAGGG) sequences in chromosomes of some domestic animals by fluorescence in situ hybridization. Hered., 123: 269-274.

45. Stone, D. M. and Stephens, K. E. (1993): Bromodeoxyuridine induces chromosomal fragile sites in canine genome. Am. J. Med. Genet., 46: 198-202.

46. Supanuam, P.; Tanomtong, A.; Jantarat, S.; Kakampuy, W; Kaewsri, S. and Kenthao, A. (2009): Standardized karyotype and idiogram of Thai native swamp buffalo, Bubalus bubalis (Artiodactyla, Bovidae) by convention staining, G-banding, C-banding and NOR-banding techniques. Thai J. Genet., 3: 83-93. 
47. Vaiman, D.; Brunialti, A.; Benaada, M.; Derboib, C.; Vaiman, A. et al (2000): Isolation of telomeric DNA sequences labelling sheep and goat chromosome ends. Genet. Sel. Evol., 32:599-619.

48. Wiscovitch, R. A; Singh, D. N. and Osborne, R. A. (1974): The relationship of slide maturity and trypsin exposure time in differential Giemsa banding of chromosomes. Staining Tech., 49:35-37.

49. Xing-tang, F.; Peng, Z.; Hong, Ch.; Yu-qun, Y. and Xiao-qin, M. (2008): Study on the karyotype and Cbanding of chromosome in Haimen White goat. J. Life Sci., 2: 1934-7391.

50. Zhuang, Z.; Wu, Z.; Zhang, S.; Pang, X.; Wang, C., and Wan, R. (2006): G-banding patterns of the chromosomes of tongue fish (Cynoglossus semilaevis). J. App. Ichth., 22: 437-440. 